\title{
Seasonal-to-Decadal Climate Forecasting
}

\author{
Emma Suckling
}

\begin{abstract}
Forecasting climate over the near-term, from a season to decades ahead, has the potential to inform decision-making within the energy sector in a number of ways: from energy trading to scheduling maintenance and resource management. Recent advances in forecasting at these timescales have led to promising levels of skill in predicting the large-scale drivers of seasonal and multi-annual climate variability as well as the consequent local climate impacts of relevance for the energy sector (e.g. seasonal temperatures and wind speeds). This chapter discusses the unique aspects of near-term prediction, how it differs from the task of weather prediction and long-term climate projections, the sources of predictability on these timescales, as well as some of the current climate forecasting tools and products aiming to provide value to the energy sector.
\end{abstract}

Keywords Seasonal-to-decadal $\bullet$ Forecasting $\bullet$ Climate $\bullet$ Predictability - Skill

E. Suckling $(\bowtie)$

NCAS-Climate, Department of Meteorology, University of Reading, Reading, UK

(C) The Author(s) 2018

A. Troccoli (ed.), Weather \& Climate Services for the Energy Industry, https://doi.org/10.1007/978-3-319-68418-5_9 


\section{Introduction to Climate Forecasting}

Climate prediction over the near-term, from seasons to multiple decades ahead, has received much attention over recent years for its potential to inform decisions in areas such as risk management and adaptation planning (Smith et al. 2012; Kirtman et al. 2013; Doblas-Reyes et al. 2013b; Meehl et al. 2014). In theory, local and regional scale forecasts on seasonalto-decadal timescales could be beneficial to the energy sector, for example in terms of understanding vulnerabilities under different energy mixes, planning future wind farm sites or developing resource management strategies. In practice, such forecasts must demonstrate that they are reliable and to add value to the practices currently adopted for decision-making.

Prediction on seasonal-to-decadal timescales occupies a middle ground between weather forecasting, whose goal is to provide a snapshot of atmospheric conditions at a particular point in time for a few days ahead, and climate projection, which aims to estimate the response to external forcings such as from greenhouse gases and aerosols. The goal of seasonal-todecadal prediction is generally to provide a statistical summary, or probability distributions, of conditions over the coming months and years given some knowledge of the current climate state, or phase of climate variability. The feasibility of predictions on these timescales arises from components of the climate system that evolve at a slower rate than the atmosphere, such as the ocean and land surface, and the interactions between them (Palmer and Hagedorn 2006; Meehl et al. 2009; Boer 2011). Sources of potential prediction skill include both externally forced low-frequency variability due to anthropogenic factors (such as greenhouse gas and aerosol concentrations and land use changes), as well as natural variations in solar activity and volcanic aerosol, and low-frequency variations within the climate system (such as large-scale modes of variability in the atmosphere and oceans).

\section{Sources of Predictability}

On seasonal timescales, the main source of predictability is the coupled ocean-atmosphere El-Niño Southern Oscillation (ENSO) phenomenon (Trenberth et al. 2000; Alexander et al. 2002; Wu et al. 2009), which has been a major factor in the success of seasonal forecasting using both dynamical and statistical models (van Oldenborgh et al. 2005; Coelho et al. 2006; Weisheimer et al. 2009; Wu et al. 2009). This mode of variability in the tropical Pacific is known to influence local-scale seasonal 
climate in many remote locations over the globe. The Madden Julian oscillation (MJO), in the tropical West Pacific and Indian Oceans, is characterised by an eastward progression of atmospheric convection (Madden and Julian 1971). Studies suggest evidence of teleconnections between the MJO and variability in the extratropics in the Pacific basin (Kim et al. 2006) and Atlantic (Cassou 2008) on monthly timescales. Seasonal predictability is also thought to arise from interactions between the troposphere and stratosphere, associated with the quasi-biennial oscillation (QBO) (Baldwin et al. 2001) and sudden stratospheric warming (SSW) (Marshall and Scaife 2010) which can have an important influence on winter conditions, particularly over Europe (Ineson and Scaife 2009). The North Atlantic Oscillation (NAO) is another source of low-frequency variability often attributed to stratosphere-troposphere coupling (Scaife et al. 2005 ) and is known to influence winter temperatures and rainfall over Northern Europe and Central Asia (Ineson and Scaife 2009; Matthes et al. 2006). Recent studies have reported skill at predicting winter NAO from seasonal forecasts using dynamical models (Scaife et al. 2014). Evidence of teleconnections between winter NAO and European climate in the following spring has also been suggested based on statistical analyses using observations (Herceg-Bulić and Kucharski 2013). The NAO has also been implicated as a predictor of Northern Hemisphere temperature variability at multidecadal timescales ( $\mathrm{Li}$ et al. 2013).

On timescales of years to decades ahead, a major source of predictability is likely to arise from slowly evolving (multidecadal) variations in sea surface temperatures (SSTs) in the North Atlantic, referred to as Atlantic Multidecadal Variability (AMV). North Atlantic SST fluctuations are linked to variability in the Atlantic Meridional Overturning Circulation (AMOC), which may vary naturally or through external influences, such as volcanoes or greenhouse gases. It has been suggested that AMV and AMOC could be potentially predictable several years ahead (Griffes and Bryan 1997; Dunstone and Smith 2010) and some evidence suggests that associated changes in climate over Europe, America and the African Sahel, as well as in the strength and position of the Atlantic storm track (Knight et al. 2006; Sutton and Hodson 2007; Sutton and Dong 2012) could also be predictable. Pacific decadal variability (PDV) is also associated with climate impacts over America, Asia, Africa and Australia on multidecadal timescales (Power et al. 1999; Deser et al. 2004); however, the processes involved are currently not well understood and evidence of potential predictability is weaker than for AMV. The Indian Ocean Dipole, characterised as a fluctuation in SSTs, 
has recently been associated with changes in winds and rainfall across Africa and India on interannual timescales (Webster et al. 1999).

In addition to large-scale modes of internally generated natural variability, the evolution of the climate system is affected by external factors, including a response to anthropogenic activity as well as natural factors such as solar activity and volcanic eruptions. Solar activity is somewhat predictable in terms of sunspot number and solar radiative output, which varies with a period of approximately 11 years. The influence of solar activity on global climate is fairly small and studies suggest global temperatures may vary by about $0.1^{\circ} \mathrm{C}$ due to solar activity (Lean and Rind 2008), as well as influence stratospheric temperatures and induce small changes in tropical atmospheric circulation (see e.g. Gray et al. 2010, Gray et al. 2016, Lockwood et al. 2010). Volcanic activity cannot be predicted in advance, but large volcanic eruptions have a significant impact on forecast skill once they have occurred. Aerosols emitted into the stratosphere affect global and local temperatures over the timescale of a year or two, as well as the hydrological cycle and atmospheric circulation. Volcanic activity can also impact ocean circulation and heat content on timescales of years or decades, which has important implications for decadal forecast skill (Marshall et al. 2009).

\section{The Probabilistic Nature of Climate Forecasting}

Climate forecasts are necessarily formulated in a probabilistic way (usually as ensembles of deterministic possible outcomes), owing to the inherently uncertain nature of climate prediction. Both the chaotic nature of the climate system (in which small errors in estimating the initial climate state grow with time in any forecast) and inadequacies of the forecast systems themselves (due to approximations in the formulation of the models and missing processes and feedbacks) contribute to forecast uncertainties, which play an important role in the interpretation and use of such forecasts for decision-making. The relative contributions of different sources of forecast uncertainty depend on the timescale, region and variable of interest, but can be difficult to disentangle (see Fig. 9.1). However, at shorter timescales, from months to years ahead, internal variability (from mechanisms such as ENSO or MJO) is typically a major source of uncertainty, accounting for the largest fraction of the variance (e.g. in global or regional temperatures) in studies based on model predictions (Hawkins and Sutton 2009). Over the near-term, up to a few decades ahead, scenario uncertainty (which is assessed through a series of possible pathways that include estimates of future greenhouse gas emissions, land use changes and socio-economic factors) is typically not a dominant source of uncer- 

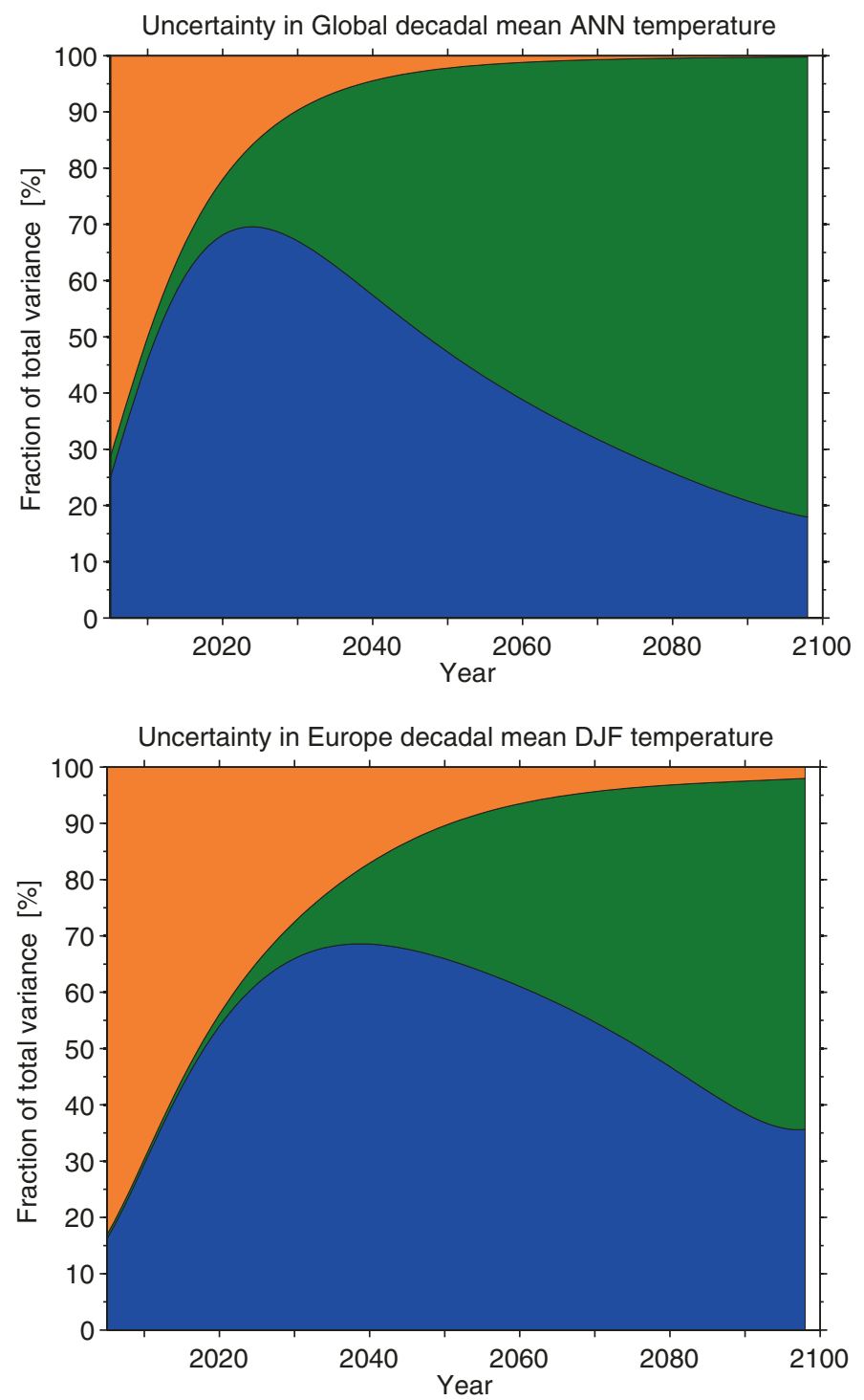

Fig. 9.1 Relative contributions to the fraction of total variance from each source of uncertainty in projections of decadal mean surface air temperature in a) global mean and b) Europe mean. Green regions represent scenario uncertainty, blue regions represent model uncertainty, and orange regions represent the internal variability component. The importance of model uncertainty is clearly visible for all policy-relevant timescales. As the size of the region is reduced, the relative importance of internal variability increases. Scenario uncertainty only becomes important at multidecadal lead times (Hawkins and Sutton 2009, see also Kirtman et al. 2013). 
tainty at these timescales and is shown to account for only a small fraction of variance in model studies. Model inadequacy accounts for a large source of uncertainty, particularly in the near-term; therefore, the evaluation and comparison of a variety of forecast approaches and models are crucial both in terms of understanding sources of predictability and skill and in terms of designing and calibrating any prediction system for operational use.

Recent progress in the development of seasonal-to-decadal prediction systems includes the use of empirical methods, dynamical models or a combination of both. Empirical methods are based on observations and exploit statistical relationships to represent physical processes. Empirical models include simple approaches such as characterising the historical climatology, or persisting current conditions, as well as more sophisticated methods such as linear regression models (e.g. Eden et al. 2015; Suckling et al. 2016), constructed analogues or neural networks (see, e.g. van den Dool 2007). However, such models rely on an adequate database of historical observations on which to train the model, which is not always available. Dynamical models approximate solutions to the fundamental physical equations that characterise the Earth system. Seasonalto-decadal predictions based on dynamical models typically involve combining a boundary condition problem (i.e. simulating the response to forcings and the feedbacks between them) with an initial condition problem, in which the current state of the atmosphere, ocean, cryosphere and land surface is estimated by initialising the model to a state close to observations through data assimilation (see, e.g. Smith et al. 2012). The aim of initialisation is to narrow uncertainty in the predictions by taking into account the phase of internal climate variability (Doblas-Reyes et al. 2013a). The process of initialisation is not trivial, however, and constraining a model with observations generally causes initialisation shocks, which impact the forecast skill. Furthermore, systematic biases cause a model to drift away from the observations over time towards its preferred climatology. Several recent studies have adopted different methodologies for attempting to overcome such biases (Balmaseda et al. 2009); however, at present the common approach to dealing with model bias and drift is to remove any systematic errors through post-processing. Postprocessing refers to approaches that are used to transform raw model output into forecast products and includes calibration (e.g. bias adjustment or downscaling) and combination (in which information from different sources and models are combined to form a single forecast) (see, e.g. Doblas-Reyes et al. 2013b). 


\section{Assessing the Quality of Climate Forecasts}

The quality of seasonal-to-decadal prediction systems is typically assessed by comparing predictions from different models against each other and against observations over a historical hindcast period (Goddard et al. 2013). Hindcasts (sometimes referred to as reforecasts) are essentially retrospective forecasts generated using today's state-of-the-art models, based on knowledge of the historical climate drivers. Several different attributes of the forecast ensemble are often quantified, including model bias and ensemble spread, as well as the correspondence between forecast and outcome pairs using a variety of statistical metrics (Jolliffe and Stephenson 2003). Such metrics include deterministic skill scores, which consider the ensemble mean properties of a set of predictions, and probabilistic skill scores (Bröcker and Smith 2007) that quantify the quality of the full distribution of ensemble members relative to a reference forecast system (such as climatology, persistence or another forecast system) (Suckling and Smith 2013). Reliability measures the correspondence between the predicted probabilities and observed frequencies of a particular set of events. The evaluation of any forecast system in this way is crucial, not only for the development and improvement of systems for operational use, but also in understanding when forecasts are likely to provide reliable information (e.g. Weisheimer and Palmer 2014).

\section{Climate Forecast Tools for the Energy Sector}

Both empirical approaches and the use of initialised dynamical prediction systems have been relatively successful for seasonal forecasting, leading to the availability of a number of operational products including the North American Multi-Model Ensemble (NMME) ${ }^{1}$ and the EUROSIP multimodel seasonal forecasting system. ${ }^{2}$ Initiatives such as the Advancing Renewable Energy with Climate Services (ARECS) and European Climatic Energy Mixes (ECEM) ${ }^{3}$ projects aim to develop state-of-the art tools and forecasts that are relevant to the energy sector (see Fig. 9.2).

The field of decadal forecasting is still relatively new, but is rapidly developing. Currently decadal predictions are not widely used as operational products; however, model intercomparison projects such as CMIP5 (Taylor et al. 2012) have advanced the science base for decadal prediction using dynamical model and projects such as the Decadal Forecast Exchange ${ }^{4}$ and the World Climate Research Programme (WRCP) Grand Challenge on Near-Term Climate Prediction (https://www.wcrp-climate.org/ 


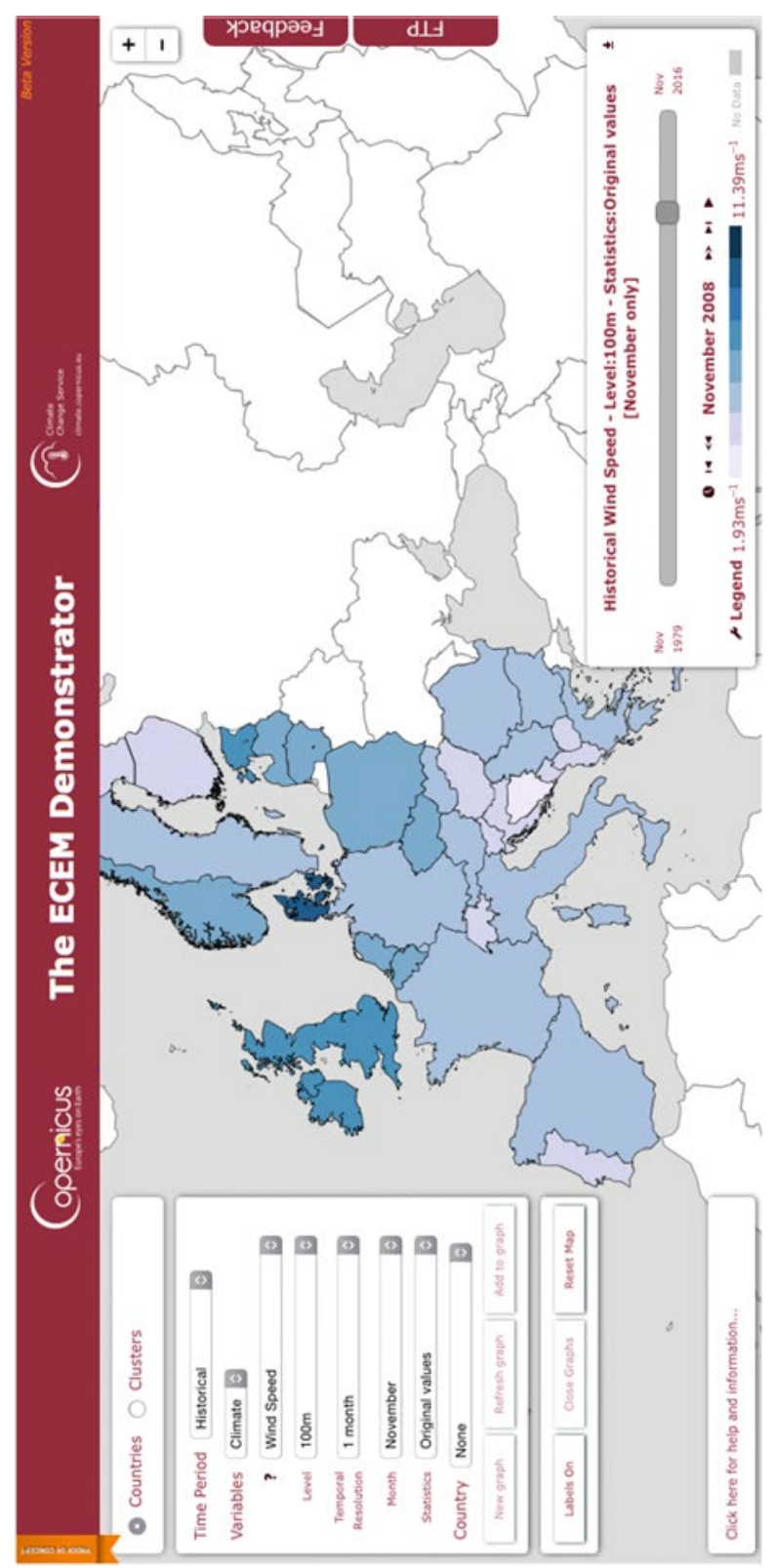

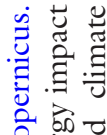

웧

记

苛苛

ฮี่

记

Хิ

ت્己

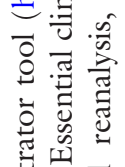

泀.

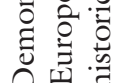

$\sum \dot{\bar{\nu}} \sigma$

至

음

¿

छี है

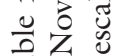

즐 司

*

节 के

อี

.

ป

4 至章

늘 즐

気

ㄷำ

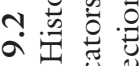

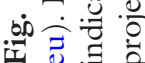


grand-challenges/gc-near-term-climate-prediction) aim to facilitate development of decadal forecast approaches towards operational use.

\section{CONCLUding Remarks}

The recent interest in seasonal-to-decadal forecasting has led to significant improvements in forecast skill, as well as a better understanding of the sources of forecast skill and climate predictability. At seasonal timescales, ENSO is reliably predicted several months ahead by the latest empirical and dynamical models, and ENSO teleconnections are also well predicted (Wang et al. 2009). Recent analyses of the reliability of seasonal forecasts have indicated that temperature predictions in the east and west coast of North America and parts of China and East Asia are reliable, particularly in winter (DJF), while predictions over South America, Southern Africa and Australia are reliable in austral winter (JJA) (see Fig. 9.3) (Weisheimer and Palmer 2014). Predictions in other regions and seasons may also be useful as decision-relevant tools; however, there is often a lot of diversity between different models, making it difficult to make statements about the broad level skill in those regions. Predictions of precipitation are generally less reliable, however. On the other hand, near surface winds are strongly constrained by the ocean in the tropics and are therefore relatively predictable. Furthermore, recent indications of skill in predicting the NAO during winter show promising signals of predictability of winter winds and temperatures in the extratropics, particularly over Europe (Scaife et al. 2014).

On decadal timescales, empirical methods have been demonstrated to represent temperatures well, both for externally forced signals (Lean and Rind 2008; Suckling et al. 2016) and for idealised studies of internal variability (Hawkins et al. 2011). There is also evidence of predictability in north Atlantic SSTs related to skill in predictions of the AMOC (Pohlmann et al. 2013); however, evaluations are currently complicated by a lack of observations over an extended period. The initialisation of model predictions has provided some evidence of improvements in AMV and other large-scale models of variability (Doblas-Reyes et al. 2013a), as well as in predictions of, for example, Atlantic hurricane number more than a year in advance (Smith et al. 2010).

The future direction of climate forecasting for the energy sector will see continued efforts in the development of climate prediction systems, including a new generation of high-resolution global and regional climate models under projects such as PRIMAVERA, ${ }^{5}$ as well as improved understanding of the mechanisms that drive local variability and impacts and the 

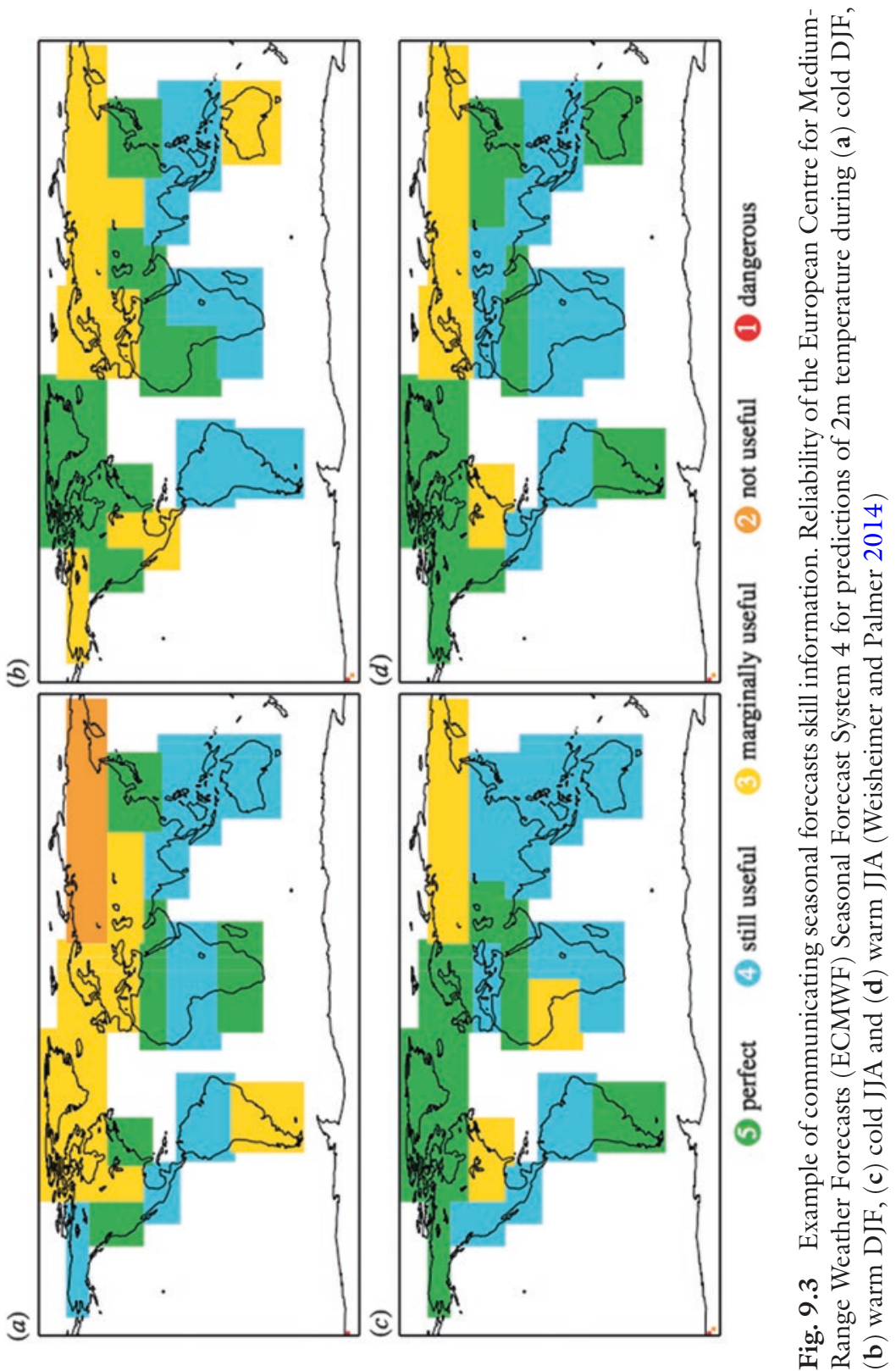
conditions which lead to greater predictability and forecast skill. Initiatives such as the Copernicus Climate Change Service (C3S-climate.copernicus.eu) and its related projects are already working towards tailoring stateof-the-art climate forecasts for the energy sector, including the delivery of energy-relevant climate variables and energy-impact indicators from a season to several decades ahead.

\section{Notes}

1. http://www.cpc.ncep.noaa.gov/products/NMME/.

2. https://www.ecmwf.int/en/forecasts/documentation-and-support/longrange/seasonal-forecast-documentation/eurosip-user-guide/multi-model.

3. http://ecem.climate.copernicus.eu.

4. http://www.metoffice.gov.uk/research/climate/seasonal-to-decadal/ long-range/decadal-multimodel.

5. https://www.primavera-h2020.eu.

\section{REFERENCES}

Alexander, M. A., et al. (2002). The atmospheric bridge: The influence of ENSO teleconnections on air-sea interactions over the global oceans. Journal of Climate, 15, 2205-2231. https://doi.org/10.1175/1520-0442(2002)015.

Baldwin, M. P., et al. (2001). The quasi-biennial oscillation. Reviews of Geophysics, 39, 179-229. https://doi.org/10.1029/1999RG000073.

Balmaseda, M., et al. (2009). Impact of initialization strategies and observations on seasonal forecast skill. Geophysical Research Letters, 36, L01701. https:// doi.org/10.1029/2008GL035561.

Boer, G. J. (2011). Decadal potential predictability of twenty-first century climate. Climate Dynamics, 36, 1119-1133. https://doi.org/10.1007/ s00382-010-0747-9.

Bröcker, J., \& Smith, L. A. S. (2007). Scoring probabilistic forecasts: The importance of being proper. Weather and Forecasting, 22, 382-388. https://doi. org/10.1175/WAF966.1.

Cassou, C. (2008). Intraseasonal interaction between the Madden Julian oscillation and the North Atlantic oscillation. Nature, 455, 523-527. https://doi. org/10.1038/nature07286.

Coelho, C. A. S., et al. (2006). Towards an integrated seasonal forecasting system for South America. Journal of Climate, 19, 3704-3721. https://doi. org/10.1175/JCLI3801.1.

Deser, C., Phillips, A. S., \& Hurrell, J. W. (2004). Pacific interdecadal climate variability: Linkages between the tropics and the North Pacific during Boreal 
Winter since 1900. Journal of Climate, 17, 3109-3124. https://doi. org/10.1175/1520-0442(2004)017<3109:PICVLB>2.0.CO;2.

Doblas-Reyes, F. J., et al. (2013a). Initialized near-term regional climate change prediction. Nature Communications, 4, 1715. https://doi.org/10.1038/ ncomms2704.

Doblas-Reyes, F. J., et al. (2013b). Seasonal climate predictability and forecasting: Status and prospects. WIREs: Climate Change, 4, 245-268. https://doi. org/10.1002/wcc. 217 .

van den Dool, H. M. (2007) Empirical methods in short-term climate prediction, Oxford University Press, Oxford. ISBN:0-19-920278-8.

Dunstone, N. J., \& Smith, D. M. (2010). Impact of atmosphere and sub-surface ocean data on decadal climate prediction. Geophysical Research Letters, 37, L02709. https://doi.org/10.1029/2009GL041609.

Eden, J. M., et al. (2015). A global empirical system for probabilistic seasonal climate prediction. Geoscientific Model Development Discussion, 8, 3941-3970. https://doi.org/10.5194/gmdd-8-3941-2015.

Goddard, L., et al. (2013). A verification framework for interannual-to-decadal prediction experiments. Climate Dynamics, 40, 245-272. https://doi. org/10.1007/s00382-012-1481-2.

Griffes, S. M., \& Bryan, K. (1997). Predictability of North Atlantic multidecadal climate variability. Science, 275(5297), 181-184. https://doi.org/10.1126/ science.275.5297.181.

Hawkins, E., \& Sutton, R. (2009). The potential to narrow uncertainty in regional climate predictions. Bulletin of the American Meteorological Society, 90, 1095. https://doi.org/10.1175/2009BAMS2607.1.

Hawkins, E., et al. (2011). Evaluating the potential for statistical decadal predictions of sea surface temperatures with a perfect model approach. Climate Dynamics, 37, 2495-2509. https://doi.org/10.1007/s00382-011-1023-3.

Herceg-Bulić, I., \& Kucharski, F. (2013). North Atlantic SSTs as a link between the wintertime NAO and the following spring climate. Journal of Climate, 27, 186. https://doi.org/10.1175/JCLI-D-12-00273.1.

Ineson, S., \& Scaife, A. A. (2009). The role of the stratosphere in the European climate response to El Niño. Nature Geoscience, 2, 32-36. https://doi. org/10.1038/ngeo381.

Jolliffe, I. T. and Stephenson, D. B. (2003) Forecast verification: A practitioner's guide in atmospheric science, Chichester; West Sussex: J. Wiley. ISBN:978-0-470-66071-3.

Kim, B.-M., Lim, B.-H., \& Kim, K.-Y. (2006). A new look at the midlatitude-MJO teleconnection in the Northern Hemisphere Winter. Quarterly Journal of the Royal Meteorological Society, 132, 485-503. https://doi.org/10.1256/qj.04.87.

Kirtman, B., et al. (2013). Near-term climate change: Projections and predictability. In T. F. Stocker, D. Qin, G.-K. Plattner, M. Tignor, S. K. Allen, J. Boschung, 
A. Nauels, Y. Xia, V. Bex, \& P. M. Midgley (Eds.), Climate change 2013: The physical science basis. Contribution of working group I to the fifth assessment report of the intergovernmental panel on climate change (pp. 953-1028). Cambridge; New York: Cambridge University Press. https://doi.org/ 10.1017/CB09781107415324.023.

Knight, J. R., Folland, C. K., \& Scaife, A. A. (2006). Climate impacts of the Atlantic Multidecadal Oscillation. Geophysical Research Letters, 33, L17706. https://doi.org/10.1029/2006GL026242.

Lean, J. L., \& Rind, D. H. (2008). How natural and anthropogenic influences alter global and regional surface temperatures: 1889 to 2006. Geophysical Research Letters, 35, L18701. https://doi.org/10.1029/2008GL034864.

Li, J., Sun, C., \& Jin, F.-F. (2013). NAO implicated as a predictor of Northern Hemisphere mean temperature multidecadal variability. Geophysical Research Letters, 40, 5497-5502. https://doi.org/10.1002/2013GL057877.

Madden, R. A., \& Julian, P. R. (1971). Detection of a 40-50 day oscillation in the zonal wind in the tropical Pacific. Journal of the Atmospheric Sciences, 28, 702-708. https://doi.org/10.1175/1520-0469(1971)028<0702:DOADOI>2.0.CO;2.

Marshall, A. G., Scaife, A. A., \& Ineson, S. (2009). Enhanced seasonal prediction of European winter warming following volcanic eruptions. Journal of Climate, 22, 6168-6180. https://doi.org/10.1175/2009JCLI3145.1.

Marshall, A. G., \& Scaife, A. A. (2010). Improved predictability of stratospheric sudden warming events in an atmospheric general circulation model with enhanced stratospheric resolution. Journal of Geophysical Research, 115, Dl6114. https://doi.org/10.1029/2009JD012643.

Matthes, K., et al. (2006). Transfer of the solar signal from the stratosphere to the troposphere: Northern winter. Journal of Geophysical Research, 111, D06108. https://doi.org/10.1029/2005JD006283.

Meehl, G. A., et al. (2009). Decadal prediction: Can it be skillful? Bulletin American Meteorological Society, 90, 1467-1485. https://doi.org/10.1175/2 009BAMS2778.1.

Meehl, G. A., et al. (2014). Decadal climate prediction: An update from the trenches. Bulletin of the American Meteorological Society, 95, 2. https://doi. org/10.1175/BAMS-D-12-00241.1.

van Oldenborgh, G.-J., et al. (2005). Did the ECMWF seasonal forecast model outperform statistical ENSO forecast models over the last 15 years? Journal of Climate, 18, 3240-3249. https://doi.org/10.1175/JCLI3420.1.

Palmer, T., \& Hagedorn, R. (Eds.). (2006). Predictability of weather and climate. Cambridge: Cambridge University Press. https://doi.org/10.1017/ CB09780511617652.

Pohlmann, H., et al. (2013). Skillful predictions of the mid-latitude Atlantic meridional overturning circulation in a multi-model system. Climate Dynamics, 41, 775-785. https://doi.org/10.1007/s00382-013-1663-6. 
Power, S., et al. (1999). Interdecadal modulation of the impact of ENSO on Australia. Climate Dynamics, 15, 319-324. https://doi.org/10.1007/ s003820050284.

Scaife, A. A., et al. (2005). A stratospheric influence on the winter NAO and North Atlantic surface climate. Geophysical Research Letters, 32, L18715. https://doi.org/10.1029/2005GL023226.

Scaife, A. A., et al. (2014). Skilful long range prediction of European and North American winters. Geophysical Research Letters, 41, 2514-2519. https://doi. org/10.1002/2014GL059637.

Smith, D. M., et al. (2010). Skilful multi-year predictions of Atlantic hurricane frequency. Nature Geoscience, 3, 846-849. https://doi.org/10.1038/ngeol004.

Smith, D. M., Scaife, A. A., \& Kirtman, B. P. (2012). What is the current state of scientific knowledge with regard to seasonal and decadal forecasting? Environmental Research Letters, 7, 015602. https://doi. org/10.1088/1748-9326/7/1/015602.

Suckling, E. B., \& Smith, L. A. (2013). An evaluation of decadal probability forecasts from state-of-the-art climate models. Journal of Climate, 26, 9334-9347. https://doi.org/10.1175/JCLI-D-12-00485.1.

Suckling, E. B., van Oldenborgh, G.-J., Eden, J. M., \& Hawkins, E. (2016). An empirical model for probabilistic decadal prediction: Global attribution and regional hindcasts. Climate Dynamics. https://doi.org/10.1007/ s00382-016-3255-8.

Sutton, R., \& Hodson, D. (2007). Climate response to basin-scale warming and cooling of the North Atlantic Ocean. Journal of Climate, 20(5), 891-907. https://doi.org/10.1175/JCLI4038.1.

Sutton, R., \& Dong, B. (2012). Atlantic Ocean influence on a shift in European climate in the 1990s. Nature Geoscience, 5, 788-792. https://doi. org/10.1038/ngeol595.

Trenberth, K. E., et al. (2000). The Southern Oscillation revisited: Sea level pressures, surface temperatures and precipitation. Journal of Climate, 13, 4358-4365. https://doi.org/10.1175/1520-0442(2000)013.

Wang, B., et al. (2009). Advance and prospectus of seasonal prediction: Assessment of the APCC/CliPAS 14-model ensemble retrospective seasonal prediction (1980-2004). Climate Dynamics, 33, 93-117. https://doi.org/10.1007/ s00382-008-0460-0.

Webster, P. J., et al. (1999). Coupled ocean-atmosphere dynamics in the Indian Ocean during 1997-98. Nature, 401, 356-360. https://doi.org/10.1038/43848.

Weisheimer, A., et al. (2009). ENSEMBLES - A new multi-model ensemble for seasonal-to-annual predictions: Skill and progress beyond DEMETER in forecasting tropical Pacific SSTs. Geophysical Research Letters, 36, L21711. https:// doi.org/10.1029/2008GL040896. 
Weisheimer, A., \& Palmer, T. (2014). On the reliability of seasonal climate forecasts. Journal of the Royal Society Interface, 11(162), 20131. https://doi. org/10.1098/rsif.2013.1162.

Wu, R., Kirtman, B. P., \& van den Dool, H. (2009). An analysis of ENSO prediction skill in the CFS retrospective forecasts. Journal of Climate, 22, 1801-1818. https://doi.org/10.1175/2008JCLI2565.1.

Open Access This chapter is distributed under the terms of the Creative Commons Attribution 4.0 International License (http://creativecommons.org/licenses/ by $/ 4.0 /$ ), which permits use, duplication, adaptation, distribution and reproduction in any medium or format, as long as you give appropriate credit to the original author(s) and the source, a link is provided to the Creative Commons license and any changes made are indicated.

The images or other third party material in this chapter are included in the work's Creative Commons license, unless indicated otherwise in the credit line; if such material is not included in the work's Creative Commons license and the respective action is not permitted by statutory regulation, users will need to obtain permission from the license holder to duplicate, adapt or reproduce the material.

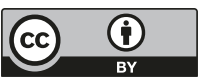

